\title{
P135 Assessment of Novel Blood Pressure Corrected Cardio-ankle Vascular Index in Response to Acute Blood Pressure Changes
}

\author{
Michal Mestanik ${ }^{1}$, Bart Spronck², Alexander Jurko Jr. ${ }^{3}$, Andrea Mestanikova ${ }^{1}$, Tomas Jurko ${ }^{4}$, Mark Butlin 5 , \\ Alberto Avolio ${ }^{5}$, Lucia Bona Olexova ${ }^{6}$, Zuzana Visnovcova ${ }^{1}$, Nikola Sekaninova ${ }^{6}$, Ingrid Tonhajzerova ${ }^{6, *}$ \\ ${ }^{1}$ Biomedical Center Martin and Department of Physiology, Jessenius Faculty of Medicine in Martin, Comenius University in Bratislava, Martin, Slovakia \\ ${ }^{2}$ Department of Biomedical Engineering, Yale University, New Haven, Connecticut, USA; Department of Biomedical Engineering, \\ CARIM School for Cardiovascular Diseases, Maastricht University, Maastricht, the Netherlands \\ ${ }^{3}$ Pediatric Cardiology, external workplace of Jessenius Faculty of Medicine in Martin, Comenius University in Bratislava, Martin, Slovakia \\ ${ }^{4}$ Neonatologic Clinic, Jessenius Faculty of Medicine in Martin, Comenius University in Bratislava, University Hospital Martin, Martin, Slovakia \\ ${ }^{5}$ Department of Biomedical Sciences, Faculty of Medicine and Health Sciences, Macquarie University, Sydney, NSW, Australia \\ ${ }^{6}$ Department of Physiology and Biomedical Center Martin, Jessenius Faculty of Medicine in Martin, Comenius University in Bratislava, Martin, Slovakia
}

\section{ABSTRACT}

Background: Cardio-ankle vascular index (CAVI) has long been considered a measure of arterial stiffness independent of short-term changes in blood pressure (BP) [1]. Recently and theoretically, CAVI was found to be partially affected by actual BP, thus, a novel BP-corrected index, $\mathrm{CAVI}_{0}$, was proposed to diminish these effects [2,3]. Direct, repeated measures experimental data comparing CAVI's and CAVI's acute blood pressure dependence is lacking. Hence, the aim of this study was to assess the effects of short-term changes of BP on CAVI in comparison with standard CAVI.

Methods: 60 healthy adults were examined using vascular screening system VaSera $1500 \mathrm{~N}$ (Fukuda Denshi Co., Tokyo, Japan) during four examination periods lasting 5 minutes - baseline, cold pressor test (CPT), recovery period, and isometric handgrip exercise (IHE). CAVI and cardiovascular parameters for calculation of $\mathrm{CAVI}_{0}$ were measured after baseline, at the peak of pressor response to CPT, after recovery period, and at the peak of pressor response to IHE. CAVI, CAVI ${ }_{0}$, and mean BP were assessed for all periods.

Results: CAVI significantly increased during CPT compared to baseline rest $(p=0.008)$, returned to baseline values during recovery period ( $p=0.011$ compared to CPT), and significantly increased during IHE compared to recovery period $(p=0.002)$. No significant changes of $\mathrm{CAVI}_{0}$ were found. CAVI significantly correlated with changes in mean $\mathrm{BP}(p=0.012$; multilevel regression); $\mathrm{CAVI}_{0} \operatorname{did}$ not $(p=0.570)$.

Conclusion: In this repeated measures, experimental, acute study, CAVI showed short-term blood pressure dependence, whereas $\mathrm{CAVI}_{0}$ did not.

\section{REFERENCES}

[1] Shirai K, Utino J, Otsuka K, Takata M. A Novel blood pressure-independent arterial wall stiffness parameter; cardio-ankle vascular index (CAVI). J Atheroscler Thromb 2006;13:101-7.

[2] Spronck B, Avolio AP, Tan I, Butlin M, Reesink KD, Delhaas T. Arterial stiffness index beta and cardio-ankle vascular index inherently depend on blood pressure but can be readily corrected. J Hypertens 2017;35:98-104

[3] Spronck B, Mestanik M, Tonhajzerova I, Jurko A, Tan I, Butlin M, et al. Easy conversion of cardio-ankle vascular index into CAVI0: influence of scale coefficients. J Hypertens 2019;37:1913-14.

(c) 2019 Association for Research into Arterial Structure and Physiology. Publishing services by Atlantis Press International B.V. This is an open access article distributed under the CC BY-NC 4.0 license (http://creativecommons.org/licenses/by-nc/4.0/). 